\title{
RAMAN SPECTROSCOPY AND X-RAY FLUORESCENCE IN MOLECULAR ANALYSIS OF YELLOW BLOCKS FROM THE ARCHEOLOGICAL SITE PLAYA MILLER 7 (NORTHERN CHILE)
}

\author{
M. SEPÚLVEDA ${ }^{1}$, S. GUTIERREZ ${ }^{1}$, M. CAMPOS-VALLETTE2, E. CLAVIJO', P. WALTER ANDJ.J. CÁRCAMO ${ }^{\prime *}$ \\ ${ }^{1}$ Laboratorio de Análisis e investigaciones arqueométricas (LAJA), Departamento de Antropología, Universidad de Tarapacá, Arica-Chile \\ ${ }^{2}$ Laboratorio de Espectroscopio Vibracional, Facultad de Ciencias, Universidad de Chile, Santiago, Chile
}

(Received: April 29, 2013 - Accepted: May 27, 2013)

\begin{abstract}
Yellow blocks from the archaeological site Playa Miller 7 (PLM7), on the coast of Atacama Desert in northern Chile, were analyzed by Raman spectroscopy and X-ray fluorescence (XRF) portable. Our results identify for the first time the use of K-jarosite and natrojarosite in prehispanic times (approx. 2500 year BP). In search of a possible source of supply for this mineral hydrothermal origin, our surveys were focused on Andean geothermal areas with identification, so far, from a single source in the region of Arica and Parinacota: Jurasi (JU), located at 4000 mamsl. Comparison of the Raman spectra between samples archaeological and Jurasi, allow us to infer that this hydrothermal source could be used as obtaining source of yellow pigment by prehispanic inhabitant of Formative period (3700-1500 years B.P.).
\end{abstract}

Keywords: Pigments, X-ray fluorescence, Raman spectroscopy, Jarosite, northern Chile.

\section{INTRODUCTION}

The use of Raman spectroscopy and X-ray fluorescence has proved to be a powerful combination of techniques for the analysis of archaeological objects $^{1-4}$. Raman spectroscopy allows obtaining structural information of various molecular systems. This technique is part of vibrational spectroscopy, allowing information of the normal modes of vibration of different molecular groups. The greatest potential of Raman relates to their specificity, sensitivity, reproducibility, applicability in-situ, spatial and spectral resolution ${ }^{5}$, besides being a non-invasive and non-destructive technique. These advantages, coupled with recent developments in Raman instrumentation, have made it possible to extend the use of this technique to the conservation and archaeology ${ }^{5-11}$. Among others, the use of Raman allowed characterizing pigments and dyes used in the preparation of manuscripts, paintings, ceramics and textiles ${ }^{12-17}$.

Moreover, X-ray fluorescence (XRF) is, undoubtedly, one of the most commonly applied techniques in conservation and archaeology ${ }^{18}$. The development of portable equipment has contributed over the last 40 years to increase its application because of its non-destructive and non-invasive characteristics, besides allowing, in many cases, in-situ analysis without sample preparation. To these characteristics adds the ability to identify the presence of elements in major and minor amounts. Finally, this technique is appreciated for its relatively low cost and short analysis ${ }^{19}$.

From the archaeological point of view, the particular conditions of the Atacama Chilean desert favour the conservation of a wide variety of archaeological materials, some of them, attributed to the different periods of the prehispanic's chronological sequence (10500- 450 years B.P.) and postSpanish contact (posterior to the fifteenth century). From the time of the first settlements in the region, pigment is registered on fibber mats in funerary contexts along the coast or as fragments found in the stratigraphy of some occupations in eaves located about $4000 \mathrm{mams}^{20}$. During the Archaic period (10500- 3500 years B.P.), the presence of color is found in other supports such as wood, leather, filling and coating of mummified bodies and rocky walls ${ }^{20-21}$. In each of these, pigment is prepared and applied as painting, ie, as a mixture containing at least one pigment and a binder. The pigment consist in manganese oxide for black $\operatorname{color}^{20}$, iron oxide for red $^{22}$, copper oxides for green ${ }^{23}$, different sorts of clay for white or grey ${ }^{24}$. In hunter-fishermen Chinchorro from Archaic period (7000- 3500 years B.P. $)^{25-26}$, these pigments are mixed to white or grey clay $^{27-28}$ to be incorporated in the stuffing bodies or applied as a surface coating. In the rock art of andean hunter gatherers the use of iron and manganese is recognised too, but with different morphologies and sizes, aluminosilicates and possibly mixed with water as binder ${ }^{21}$.

Until now in South America, yellow pigments have received little attention. Moreover yellow pigment such as natrojarosite, has only been reported in the cave paintings of Inca Cave 4 site in the region of Jujuy, Argentina ${ }^{29}$ and other various sites in Patagonia Argentina ${ }^{30}$. The use of jarosites in South America joins other known cases as in, for example, the old world and the Egyptian Old
Kingdom (2300 - 2600 year BC $)^{31}$ or in the murals of Beroe fortress, Romania $(4 \text { th-6th century })^{32}$. Jarosites are a large family of minerals that have a general formula of the type $\mathrm{M}_{n}\left(\mathrm{Fe}^{3+}\right)_{6}\left(\mathrm{SO}_{4}\right)_{4}(\mathrm{OH})_{12}$, where $\mathrm{M}$ can be $\mathrm{K}^{+},\left(\mathrm{NH}_{4}\right)^{+}, \mathrm{Na}^{+}$, $\mathrm{Ag}^{+}$or $\mathrm{Pb}^{2+}$ and where $n=2$ for monovalent cations and 1 for the divalent cations $^{33}$. The mineralogical characteristics and chemical properties of this family of compounds have been widely studied ${ }^{33-37}$.

In this paper, we present the results obtained from the analysis by Raman spectroscopy and XRF of samples of yellow pigment blocks from the PLM7 Site, located on the coast of northern Chile (fig. 1). This colour is very rarely found in contexts archaic hunter-gatherer groups. Until now, yellow paint has only been identified on coating of a mummy of the Macarena Chinchorro site ${ }^{38}$ and in rock art paintings of Andean foothills but without analyses. Samples analyzed here have a very clear yellow colour and very bright, which may acquire an ocher tonality. Thus the aim of this paper is to account for the first time of using minerals jarosites family in Chile, in ancient times (37001500 years BP). Moreover, this work represents the first application of these techniques to the analysis of archaeological remains in Chile.

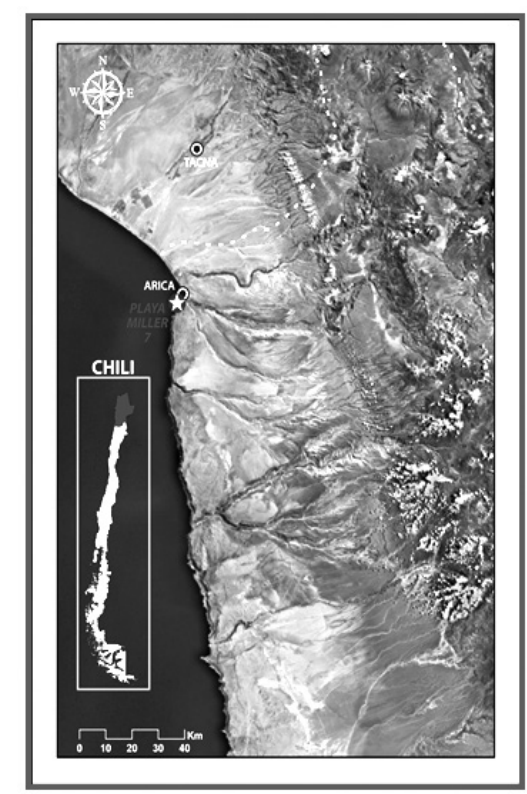

Figure 1: Map of Playa Miller 7 on the coast of northern Chile. 


\section{Experimental}

\subsection{Samples}

PLM7 samples were taken in the laboratories of the University of Tarapacá Museum of San Miguel de Azapa. These blocks come from yellow ovoid block, with compact to semi-compact structure (Table 1 and fig. 2). Many of them have linear fingerprint extraction, so that these blocks can be intentionally manufactured as a product, probably to store the pigment for his use at different times as needed. Blocks consist mainly of finely ground pigment that adheres very easily. In some cases blocks have a more heterogeneous composition visible to the naked eye, given the presence of finely ground elongated structures and incorporated in the mixture, identified as algae ${ }^{39}$. For sampling, we privileged unarmed blocks, detached fragments or powder (fig. 2). Each sample was stored in a plastic container to be moved and then analyzed.

Table 1: Results obtained by magnifying glass and XRF from samples taken from PLM7 and Jurasi.

\begin{tabular}{|l|l|l|}
\hline \multicolumn{1}{|c|}{ CODE } & \multicolumn{1}{|c|}{ TEXTURE } & \multicolumn{1}{|c|}{ ELEMENT BY XRF } \\
\hline PLM7-14 & $\begin{array}{l}\text { Ovoidal homogeneous block } \\
\text { with a very fine granulometry } \\
\text { (powder) }\end{array}$ & $\mathrm{S}, \mathrm{Cl}, \mathrm{K}, \mathrm{Ca}, \mathrm{Ti}, \mathrm{Cr}, \mathrm{Fe}$ \\
\hline PLM7-15 & $\begin{array}{l}\text { Ovoidal homogeneous block } \\
\text { with a very fine granulometry } \\
\text { (powder) }\end{array}$ & $\mathrm{S}, \mathrm{Cl}, \mathrm{K}, \mathrm{Ca}, \mathrm{Ti}, \mathrm{Cr}, \mathrm{Fe}$ \\
\hline JU-17 & Powder & $\mathrm{S}, \mathrm{Cl}, \mathrm{K}, \mathrm{Cr}, \mathrm{Fe}$ \\
\hline JU-18 & Powder & $\mathrm{S}, \mathrm{Cl}, \mathrm{K}, \mathrm{Ti}, \mathrm{Fe}$ \\
\hline
\end{tabular}

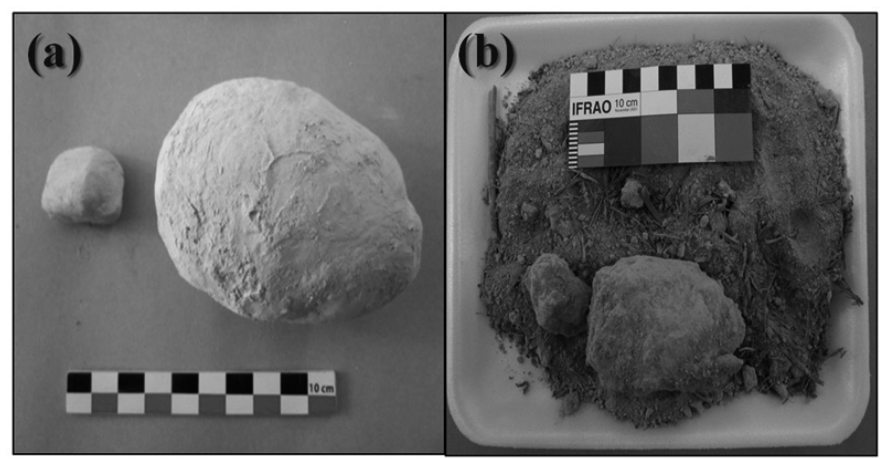

Figure 2: Type samples analyzed by yellow blocks, (a) ovoidal and (b) powder

Additionally, surveys were conducted in different areas of the region, which could be places of supply's pigments in ancient times. Recent mining uses difficult to find evidence related to the extraction of pigment in the past. So far, only the area known as Los Pumas evidence remains linked to a mining prehispanic ${ }^{20}$. Regarding yellow sources analyzed in this study, only JU area showed reservoir similar to the colour identified in PLM7. This search was conducted in order to reproduce the conditions of exploration occurred in the past.

\subsection{Analytical measurement}

Raman spectra of the yellow blocks extracted from Playa Miller 7 and Jurasi were recorded on a Raman Renishaw Microscope System RM1000 apparatus, equipped with 514, 633, and $785 \mathrm{~nm}$ laser lines for excitation, a Leica microscope and an electrically cooled charge-coupled device detector. The instrument was calibrated using the $520 \mathrm{~cm}^{-1}$ line of a Si wafer and a $50 \times$ objective. The resolution was set to $4 \mathrm{~cm}^{-1}$, and 5-20 scans of $10 \mathrm{~s}$ each were averaged; spectra were recorded in the $1800-200 \mathrm{~cm}^{-1}$ region to observe the Raman spectra. The spectral scanning conditions were chosen to avoid sample degradation and photodecomposition. Data were collected and plotted using the programs WIRE 2.0 and GRAMS 8.0.

XRF spectra were recorded with a XRF Bruker Tracer III-SD portable equipment with a detector fitted $10 \mathrm{~mm}^{2}$ XFlash $\AA$ SDD, Peltier cooled; typical resolution $145 \mathrm{eV}$ at $100000 \mathrm{cps}$ and equipped with a X-ray tube Rh target; max. voltage $40 \mathrm{keV}$, using $15 \mathrm{keV}$ of energy and an acquisition time of $120 \mathrm{~s}$. Data were collected and plotted using the program Tracer software S1PXRF 3.8.3.

\section{RESULTS}

A total of seven samples from the archaeological of PLM7 site and 3 extracted from the JU hydrothermal site were analysed. Raman spectra were recorded on different zones for each sample. Each spectrum obtained was compared with data published in RRUFF online databases ${ }^{40}$. In most of the yellow blocks of heterogeneous composition, containing algae, it was not possible to obtain the Raman spectrum due to fluorescence. Only in two cases it was possible to analyse the spectrum. The spectral scanning was performed in sample areas where yellow tonality was clearly distinguished. Furthermore, two of the three yellow blocks from the hydrothermal JU, display an analysable spectrum. All registered Raman spectra of yellow zones, showed characteristic bands ascribed to the jarosite family (fig. 3).

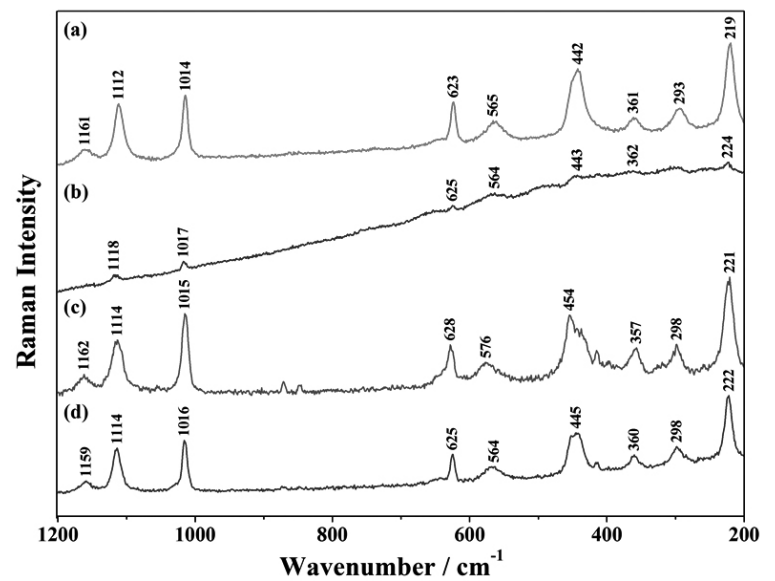

Figure 3: Raman spectrum of natrojarosite extracted from the (a) Playa Miller 7 Archaeological Site (PLM7-14), (b) Playa Miller 7 Archaeological Site (PLM7-15), (c) Jurasi hydrothermal site (JU-17) and (c) Jurasi hydrothermal site (JU-18).

Different jarosite synthetic compounds were identified by Sasaki et al. ${ }^{37}$ by using Raman, infrared and $\mathrm{X}$ ray data. They assigned different vibrational modes for the $\mathrm{SO}_{4}{ }^{2-}$ molecular fragment $\left(v_{1}, v_{2}, v_{3}\right.$ y $\left.v_{4}\right) . v_{1}$ and $v_{3}$ correspond to symmetric $\left(v_{\mathrm{s}}\right)$ and antisymmetric $\left(v_{\mathrm{as}}\right)$ stretching, respectively. The $v_{2}$ and $v_{4}$ modes correspond to bending $(\delta)$ vibrations. Other features observed in the vibration spectra of jarosites are associated with the $\mathrm{FeO}$ fragment. The spectral assignment in Table 2 is proposed on the basis of works by Sasaki et al..$^{37}$ and Frost et al. ${ }^{36}$ and general spectral data ${ }^{41}$. In our Raman spectra (fig. 3), the $v_{\mathrm{s}} \mathrm{SO}_{4}^{2-}$ mode is observed in the 1014-1017 $\mathrm{cm}^{-1}$ range. $\mathrm{A}_{\mathrm{as}} \mathrm{SO}_{4}^{2-}$ mode is ascribed in all spectra to signals in the $1112-1118 \mathrm{~cm}^{-1}$ region. Another $\mathrm{v}_{\mathrm{sS}} \mathrm{SO}_{4}^{2-}$

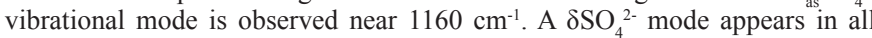
spectra in the $623-628 \mathrm{~cm}^{-1}$ range. Another $\delta \mathrm{SO}^{2-}{ }^{2-}$ vibrational mode is assigned to the band located in the region $442-454 \mathrm{~cm}^{-1}$, following Frost et al. ${ }^{36}$. The single band observed at $565 \mathrm{~cm}^{-1}$ in the spectrum of the PLM7-14 samples is assigned to $\mathrm{FeOH}$ deformation modes. The strong band in all spectra in the $219-224 \mathrm{~cm}^{-1}$ range is assigned to one of the vibration modes of the $\mathrm{Fe}-\mathrm{O}$ bond. Two bands in the $280-370 \mathrm{~cm}^{-1}$ spectral range are assigned to $\mathrm{FeO}$ vibrations.

Table 2. Wavenumbers and the most probable assignment for the Raman bands of jarosites from PLM7 and JU.

\begin{tabular}{|c|c|c|c|c|}
\hline PLM7-14 & PLM7-15 & JU-17 & JU-18 & Assignment \\
\hline $1161 \mathrm{w}$ & & $1162 \mathrm{w}$ & $1159 \mathrm{w}$ & $v_{\mathrm{as}}\left(\mathrm{SO}_{4}{ }^{2-}\right)$ \\
\hline $1112 \mathrm{~m}$ & $1118 \mathrm{~m}$ & $1114 \mathrm{~m}$ & $1114 \mathrm{~m}$ & $\mathrm{v}_{\mathrm{as}}\left(\mathrm{SO}_{4}{ }^{2-}\right)$ \\
\hline $1014 \mathrm{~ms}$ & $1017 \mathrm{~ms}$ & $1015 \mathrm{~ms}$ & $1016 \mathrm{~ms}$ & $v_{\mathrm{s}}\left(\mathrm{SO}_{4}{ }^{2-}\right)$ \\
\hline $623 \mathrm{~m}$ & $625 \mathrm{~m}$ & $628 \mathrm{~m}$ & $625 \mathrm{~m}$ & $\delta\left(\mathrm{SO}_{4}{ }^{2-}\right)$ \\
\hline $565 \mathrm{mw}$ & $564 \mathrm{mw}$ & $576 \mathrm{mw}$ & $564 \mathrm{mw}$ & $\gamma \mathrm{FeOH}$ \\
\hline $442 \mathrm{~ms}$ & $443 \mathrm{~ms}$ & $454 \mathrm{~ms}$ & $445 \mathrm{~ms}$ & $\delta\left(\mathrm{SO}_{4}{ }^{2-}\right)$ \\
\hline $36 \mathrm{~m}$ & $362 \mathrm{~m}$ & $357 \mathrm{~m}$ & $360 \mathrm{~m}$ & $\mathrm{O}-\mathrm{Fe}$ \\
\hline $293 \mathrm{~m}$ & & $298 \mathrm{~m}$ & $298 \mathrm{~m}$ & $\mathrm{O}-\mathrm{Fe}$ \\
\hline $219 \mathrm{vs}$ & $224 \mathrm{vs}$ & $221 \mathrm{vs}$ & $222 \mathrm{vs}$ & $\mathrm{O}-\mathrm{Fe}$ \\
\hline
\end{tabular}

Band description: vw, very weak; $\mathrm{w}$, weak; mw, medium weak; m, medium ; ms, medium strong; sh, shoulder; s, strong. 
To distinguish different types of jarosites in natural samples is difficult due to their heterogeneity. Therefore, we decided to realise complementary XRF analysis.

XRF analysis of yellow blocks from PLM7 and JU showed significant amounts of $\mathrm{S}$ and $\mathrm{Fe}$ (fig. 4), which is consistent with the presence of compounds of the jarosites family. Furthermore, the significant amount of K, suggests that $\mathrm{K}$-jarosite is present in samples. Under the conditions of XRF measurement, it was not possible to detect the presence of $\mathrm{Na}$ (Table 1). However, in our previous work by SEM-EDX and X-ray diffraction ${ }^{39}$, we detected the presence of this element in PLM7's samples. Finally, the absence of vibration modes associated with the molecular N-H fragment in Raman spectra, as well as the absence of the metals $\mathrm{Ag}$ and $\mathrm{Pb}$ in the XRF analysis, suggest in PLM7 and JU the presence of K-jarosite and Na-jarosite.

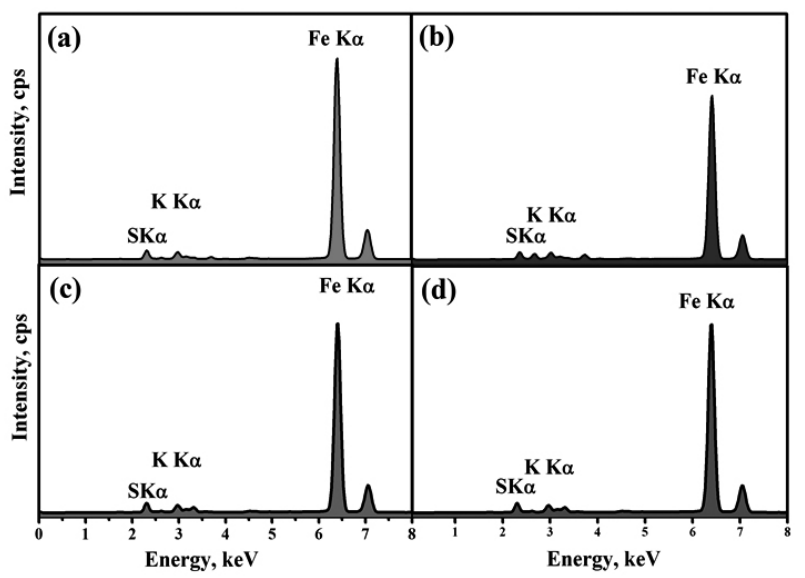

Figure 4: X-Ray spectrum of natrojarosita extracted from the (a) Playa Miller 7 Archaeological Site (PLM7-14), (b) Playa Miller 7 Archaeological Site (PLM7-15), (c) Jurasi hydrothermal site (JU-17) and (c) Jurasi hydrothermal site (JU-18)

\section{CONCLUSIONS}

Results obtained by Raman spectroscopy indicate that several of the observed vibrational signals correspond to vibration normal modes associated with jarosite type compounds. Slight differences in wavenumbers are not enough to differentiate the type of jarosite. However, from our XRF results, and previous results obtained by SEM-EDX and $\mathrm{XRD}^{40}$, we conclude that in the yellow blocks accruing from archaeological site PLM7 and font hidrotermal $\mathrm{JU}$, predominant yellow pigments are Natrojarosite and K-jarosite.

Alongside K-jarosite and Natrojarosite used as base and principal material in the yellow blocks, it is possible to find other elements such as algae and quart $^{39}$. While, Sepulveda et. al. were able to determine the presence of Natrojarosite by SEM-EDX and XRD in these same yellow blocks, it was not until this work that identify more specifically jarosites mixtures used by the prehispanic inhabitant of the coastal Atacama desert.

\section{ACKNOWLEDGEMENTS}

This work was financially supported by project FONDECYT 1100354 "Tecnología, función y significado del uso de colores en poblaciones arcaicas del extremo norte de Chile". MCV and REC acknowledge support from FONDECYT 1110106 "Vibrational spectroscopy for the study of artwork materials in the Chilean cultural heritage". MS, SG and JJC acknowledge projects MECESUP UTA 0801 and Convenio de Desempeño HCSA Universidad de Tarapacá- MINEDUC.

\section{REFERENCES}

1 K. S. Andrikopoulos, S. Daniilia, B. Roussel, K. Janssens Journal of Raman Spectroscopy. 37, 1026, (2006).

2 K. Castro, S. Pessanha, N. Proietti, E. Princi, D. Capitani, M. L. Carvalho, J. M. Madariaga, Analytical and Bioanalytical Chemistry. 391, 433, (2008).

3 T. D. Chaplin, R. J. H. Clark, M. Martinón-Torres, Journal of Molecular Structure. 976, 350, (2010).
4 F. Rosi, V. Manuali, T. Grygar, P. Bezdicka, B. G. Brunetti, A. Sgamellotti, L. Burgio, C. Seccaroni, C. Miliani, Journal of Raman Spectroscopy. 42, 407, (2011).

5 L. Burgio, R. J. H. Clark, V. S. F. Muralha, T. Stanley, Journal of Raman Spectroscopy. 39, 1482, (2008).

6 L. Bellot-Gurlet, S. Pagès-Camagna, C. Coupry, Journal of Raman Spectroscopy. 37, 962, (2006)

7 D. Bersani, P. P. Lottici, F. Vignali, G. Zanichelli, Journal of Raman Spectroscopy. 37, 1012, (2006).

8 E. Ciliberto, G. Spoto, Modern analytical methods in art and archaeology. Editor, Wiley New York, 2000.

9 R. J. H. Clark, Applied Physics A. 89, 833, (2007).

10 G. D. Smith, R. J. H. Clark, Journal of Archaeological Science. 31, 1137, (2004).

11 P. Vandenabeele, H. G. M. Edwards, L. Moens, Chemical Reviews. 107, $675,(2007)$.

12 T. Aguayo, E. Clavijo, F. Eisner, C. Ossa-Izquierdo, M. M. CamposVallette, Journal of Raman Spectroscopy. 42, 2143, (2011).

13 E. Casanova-González, A. García-Bucio, J. L. Ruvalcaba-Sil, V. SantosVasquez, B. Esquivel, T. Falcón, E. Arroyo, S. Zetina, M. L. Roldán, C. Domingo, Journal of Raman Spectroscopy. 43, 1551, (2012).

14 E. Casanova-González, A. García-Bucio, J. L. Ruvalcaba-Sil, V. Santos-Vasquez, B. Esquivel, M. L. Roldán, C. Domingo, MRS Online Proceedings Library. 1374, 263, (2012).

15 S. Lahlil, M. Lebon, L. Beck, H. Rousselière, C. Vignaud, I. Reiche, M. Menu, P. Paillet, F. Plassard, Journal of Raman Spectroscopy. 43, 1637, (2012).

16 A. Rosalie David, H. G. M. Edwards, D. W. Farwell, D. L. A. De Faria, Archaeometry. 43, 461, (2001).

17 E. Tomasini, G. Siracusano, M. S. Maier, Microchemical Journal. 102, 28, (2012)

18 D. A. Scott, Archaeometry, 43, 475, (2001).

19 L. Moens, A. von Bohlen, P. Vandenabeele, in Modern Analytical methods in Art and Archaeology, ed. by E. Ciliberto, G. Spoto, Wiley Sons, New York, (2000); Vol. 155, pp. 55.

20 M. Sepúlveda, D. Valenzuela, L. Cornejo, H. Lienqueo, H. Rousseliére, Chungara. 45, 141, (2013).

21 M. Sepulveda, E. Laval, L. Cornejo, J. Acarapi, Rock Art Research. 29, 93, (2012).

22 B. T. Arriaza, Cultura Chinchorro, las momias artificiales más antiguas del mundo. Editor, Editorial Universitaria, 2003.

23 B. Bittman, J. Munizaga in Actas del VII Congreso de Arqueología Chilena. Altos de Vilches, Ediciones Kultrún, 1977; pp. 119-130.

24 B. T. Arriaza, L. Cornejo, H. Lienqueo, V. G. Standen, C. M. Santoro, N. Guerra, J. V. Hoesen, M. Santos, Chungará. 44, 177, (2012).

25 B. Arriaza, Latin American Antiquity. 6, 35, (1995).

26 V. G. Standen, Latin American Antiquity. 8, 134, (1997).

27 B. T. Arriaza, L. Cornejo, H. Lienqueo, V. G. Standen, C. M. Santoro, N. Guerra, J. V. Hoesen, M. Santos, Chungará. 44, 177, (2012).

28 J. Van Hoesen, B. Arriaza, Archaeometry. 53, 986, (2011).

29 G. Rial, C. Barbosa, Cuadernos del Instituto Nacional de Antropología, Argentina. 10, 307, (1983).

30 M. T. Boschin, M. S. Maier, G. I. Massaferro, L'Anthropologie, 115, 360, (2011).

31 J. Ambers, Journal of Raman Spectroscopy. 35, 768, (2004).

32 N. Buzgar, A. Buzatu, A. I. Apopei, D. Aștefanei, F. Topoleanu, Analele Stiințifice ale Universității "Alexandru ioan Cuza" din Iași, seria Geologie. 57, 15, (2011).

33 R. L. Frost, R.-A. Wills, M. L. Weier, W. Martens, S. Mills, Spectrochimica Acta Part A: Molecular and Biomolecular Spectroscopy. 63, 1, (2006).

34 C. H. Chio, S. K. Sharma, D. W. Muenow, Spectrochimica Acta Part A: Molecular and Biomolecular Spectroscopy. 61, 2428, (2005).

35 G. A. Desborough, K. S. Smith, H. A. Lowers, G. A. Swayze, J. M. Hammarstrom, S. F. Diehl, R. W. Leinz, R. L. Driscoll, Geochimica et Cosmochimica Acta. 74, 1041, (2010).

36 R. L. Frost, R. A. Wills, M. L. Weier, W. Martens, Journal of Raman Spectroscopy. 36, 435, (2005).

37 K. Sasaki, O. Tanaike, H. Konno, The Canadian Mineralogist. 36, 1225, (1998).

38 B. Arriaza, V. Standen, Catalogo Momias Chinchorro. Museo Arqueológico Universidad de Tarapacá, Arica. UTA- CIHDE, Arica, 2009.

39 M. Sepúlveda, H. Rousseliere, E. V. Elslande, J. Cárcamo, P. Walter, Libro Jornadas de Bienes Culturales, Argentina, In press, 2013. 
40 R. Downs, in Book The RRUFF Project: an integrated study of the chemistry, crystallography, Raman and infrared spectroscopy of minerals. 2006.
41 V. Lin, N. B. Colthup, W. G. Fateley, J. G. Grasselli, The handbook of infrared and raman characteristic frequencies of organic molecules, Academic Press, Boston, 1991. 